\title{
PENGARUH BAHAN TAMBAH SERBUK BAN BEKAS PADA KONSTRUKSI HOTROLLED SHEET-WEARING COURSE
}

\author{
Blima Oktaviastuti ${ }^{1}$, Arinda Leliana $^{2}$, dan Luthfil Abid $^{3}$ \\ ${ }^{I}$ Program Studi Teknik Sipil, Fakultas Teknik, Universitas Tribhuwana Tunggadewi, Malang \\ ${ }^{2}$ Program Studi Manajemen Teknologi Perkeretaapian, Politeknik Perkeretaapian Indonesia, Madiun \\ ${ }^{3}$ Jurusan Teknik Sipil, Fakultas Teknik, Universitas Negeri Malang, Malang
}

E-mail: blima.oktavia90@gmail.com,arindaleliana21@gmail.com,luthfilabid37@gmail.com

\begin{abstract}
ABSTRAK: Penelitian ini bertujuan mengetahui pemanfaatan serbuk ban bekas sebagai bahan tambahan pada konstruksi jalan. Benda uji Kadar Aspal Optimum (KAO) masing-masing dibuat 3 buah dengan kadar aspal 4\%, 4,5\%, $5 \%, 5,5 \%, 6 \%$, dan 6,5\%. Benda uji dengan tambahan serbuk ban bekas masing-masing dibuat 3 buah dengan kadar serbuk ban karet bekas $0 \%, 1,5 \%, 3 \%, 4,5 \%$, dan $6 \%$. Hasil penelitian ini menunjukkan bahwa KAO sebesar 6,03\%. Kemudian untuk Parameter Marshall (PM) berdasarkan penambahan limbah serbuk ban bekas diperoleh hasil: (1) nilai PM 0\% untuk nilai stabilitas $2224 \mathrm{~kg}$, nilai flow 3,98 mm, nilai MQ $552 \mathrm{~kg} / \mathrm{mm}$, nilai VIM 4,01\%, VMA 19,70\% dan VFA 79,67\%; (2) nilai PM 1,5\% untuk nilai stabilitas $2296 \mathrm{~kg}$, nilai flow 4,53 mm, nilai MQ $509 \mathrm{~kg} / \mathrm{mm}$, nilai VIM 3,82\%, nilai VMA 19,63\% dan nilai VFA 80,54\%; (3) nilai PM 3\% untuk nilai stabilitas $1674 \mathrm{~kg}$, nilai flow 4,57 mm, nilai MQ $367 \mathrm{~kg} / \mathrm{mm}$, nilai VIM 2,78\%, VMA 19,20\%, dan nilai VFA 85,50\%; (4) nilai PM 4,5\% untuk nilai stabilitas $1055 \mathrm{~kg}$, nilai flow 4,45 mm, nilai MQ $247 \mathrm{~kg} / \mathrm{mm}$, nilai VIM 2,42\%, nilai VMA 19,04\% dan nilai VFA 87,30\%; (5) nilai PM 6\% untuk nilai stabilitas $1075 \mathrm{~kg}$, nilai flow 4,60 mm, nilai MQ $228 \mathrm{~kg} / \mathrm{mm}$, nilai VIM 1,95\%, nilai VMA $18,85 \%$, dan nilai VFA $89,63 \%$.
\end{abstract}

Kata Kunci: Serbuk Ban Bekas, Bahan Tambahan, HRS-WC

\section{PENDAHULUAN}

Kebutuhan sarana dan prasarana transportasi sangat diperlukan oleh negara maju seperti Indonesia. Transportasi memiliki peran penting dalam mensukseskan pembangunan. Pembangunan dan pemeliharaan jalan harus diperhatikan agar hubungan antar daerah tidak terputus. Oleh sebab itu, peran dari penunjang kebutuhan transportasi memegang peranan penting.

Kondisi tersebut belum berlaku di Indonesia dengan presentase terbesar kerusakan jalan diakibatkan oleh konstruksi jalan yang tidak memenuhi standar dan adanya pengendalian air yang buruk. Kencana (https://www.liputan6.com, diakses 23 April 2020) bahwa menurut Himpunan Pengembang Jalan Indonesia (HPJI) terdapat tiga faktor penyebab kerusakan jalan di Indonesia, meliputi: (1) proses desain; (2) proses pelaksanaan; dan (3) proses pemanfaatan

Perkembangan transportasi darat di Indonesia yang semakin maju menghasilkan banyak limbah kendaraan bermotor, salah satunya adalah limbah ban bekas. Serbuk ban bekas diperoleh dari vulkanisir ban karet memiliki potensi yang dapat dimanfaatkan dalam campuran aspal beton. Hasil campuran tersebut bermanfaat untuk meningkatkan stabilitas dan durabilitasnya. Pada proses perencanaan perkerasan jalan, material yang digunakan meliputi agregat, aspal, dan filler sebagai bahan pengisi campuran aspal beton.

Bukit, N. dan Frida, E. (2011:124) bahwa terdapat sekitar enam ribu ton ban bekas dihasilkan setiap tahun di Eropa, Amerika, dan Jepang yang akan terus meningkat sejalan dengan meningkatnya industri otomotif dunia. Upaya pemusnahan dengan cara pembakaran yang biasa dilakukan dapat menimbulkan dampak polusi yang berbahaya, karena berpengaruh buruk pada kesehatan manusia. Perlu adanya suatu usaha yang serius untuk menangani dan mengolah limbah ban bekas tersebut agar tidak menimbulkan masalah terhadap lingkungan.

Serbuk ban bekas yang digunakan dalam campuran aspal beton berupa hasil parutan ban kendaraan yang biasa dikenal sebagai scrap tire rubber. Serbuk ban bekas merupakan limbah dari vulkanisir ban sehingga harganya lebih murah. Mashuri dan Batti (2011:206) menyimpulkan bahwa kandungan kimia serbuk ban bekas berdasarkan hasil pengujian laboratorium kimia ITB Bandung meliputi: Karbon (32,19\%); Silikat (1,6\%); Sulfur (2,13\%); Karet (64,04\%). Hasib (2008) dalam penelitiannya, mendapatkan hasil bahwa kadar aspal optimum dengan penambahan ban karet 1\%, 2\%, 3\%, 4\%, $5 \%$, dan $6 \%$, diperoleh hasil stabilitas, Flow, VIM, VMA yang lebih tinggi, sedangkan nilai Marshall Quotient lebih kecil dibandingkan dengan nilai pada kadar aspal optimum tanpa penambahan kadar dan ban karet. Leksminingsih (2005) dalam penelitiannya bahwa perencanaan campuran aspal yang menggunakan bahan tambah katalis bekas $0 \%, 5 \%, 7,5 \%$ dan $10 \%$ dengan spesifikasi AC-WC, pada penambahan 5\% katalis menghasilkan stabilitas Marshall sebesar 1350kg, lebih tinggi 22,2\% terhadap campuran standar tanpa bahan tambah. Campuran standar mempunyai stabilitas Marshall $1050 \mathrm{~kg}$ dan stabilitas dinamis 2864 lintasan/mm. Penelitian tersebut digunakan sebagai acuan komposisi campuran serbuk ban bekas dengan kapur. Perencanaan campuran aspal dengan penambahan serbuk ban bekas dapat menggunakan $2 \%, 4 \%, 6 \%, 8 \%$ dan $10 \%$.

Berdasarkan uraian tersebut, tulisan ini bertujuan: (1) mengetahui kadar aspal optimum yang dibutuhkan untuk menentukan benda uji, dan (2) mengetahui parameter Marshall yang ditinjau dari penambahan limbah ban bekas sebesar $0 \% ; 1,5 \% ; 3 \% ; 4,5 \%$; dan $6 \%$. 


\section{METODE PENELITIAN}

Penelitian ini menggunakan metode kuantitatif dan rancangan penelitian eksperimen.

\section{1) Bahan Penelitian}

Material yang dipergunakan dalam penelitian ini meliputi:

- Aspal keras penetrasi 60/70

- Agregat

- Serbuk ban bekas tertahan di saringan No.30 lolos saringan No. 12

- Bahan pengisi (filler)

- Bahan-bahan lain yang menunjang penelitian seperti: gas elpiji, minyak tanah, solar, bensin dan oli.

2) Alat

Peralatan utama yang digunakan adalah alat uji tekan Marshall yang terdiri dari :

1) Kepala penekan berbentuk lengkung.

2) Cincin penguji/proving ring berkapasitas $22,2 \mathrm{KN}$ (5000 lbf dan 10000 lbf) yang dilengkapi dengan arloji tekan dengan ketelitian $0,0025 \mathrm{~cm}(0,001$ inch).

3) Arloji penunjuk nilai kelelehan.

\section{PELAKSANAAN PENELITIAN}

Secara garis besar penelitian ini memiliki 3 tahapan dalam pelaksanaannya. Tahapan tersebut meliputi:

1) Tahap Persiapan Penelitian

- Mencari rujukan-rujukan dari buku, surat kabar, majalah, internet dan sumber lainnya yang masih berhubungan dengan penelitian

- Menyiapkan bahan penelitian yang memenuhi syarat

- Menyiapkan peralatan laboratorium

\section{2) Tahap Pelaksanaan Penelitian}

- Memeriksa bahan penelitian dengan cara laboratorium yang terdiri dari agregat dan aspal keras 60/70

- Menyiapkan dan membuat benda uji kontrol campuran agregat ditambah aspal

- Melakukan pengujian dengan alat Marshall

- Membuat benda uji kontrol (tanpa campuran serbuk ban bekas)

- Membuat benda uji penelitian campuran aspal + agregat + serbuk ban bekas. Kadar serbuk ban bekas adalah $0 \%, 1,5 \%, 3 \%, 4,5 \%$, dan $6 \%$

- Melakukan pengetesan dengan alat Marshall

\section{3) Tahap Penyelesaian Penelitian}

- Melakukan analisis data

- Membuat draft laporan

\section{HASIL}

\section{1) Pengujian Agregat}

Hasil pengujian agregat kasar dan agregat halus dengan persyaratan sesuai dengan spesifikasi Pelaksanaan Lapis Campuran Beraspal Panas Revisi SNI 03-17371989, dapat dilihat pada Tabel 1 di bawah ini:

2) Pengujian Aspal

Hasil pengujian aspal keras penetrasi 60/70 sesuai dengan spesifikasi Pelaksanaan Lapis Campuran Beraspal
Panas Revisi SNI 03-1737-1989, dapat dilihat pada Tabel 2 berikut:

Tabel 1. Hasil Pengujian Agregat

\begin{tabular}{|c|l|c|c|}
\hline No. & Pengujian & Hasil & Spesifikasi \\
\hline & Agregat Kasar & & \\
\hline 1. & Berat Jenis $\left(\mathrm{gr} / \mathrm{cm}^{3}\right)$ & 3,08 & Min. 2,5 \\
\hline 2. & Penyerapan $(\%)$ & 2,29 & Max. 3 \\
\hline 3. & Keausan $(\%)$ & 35,22 & Max. 40 \\
\hline & Agregat Halus & & \\
\hline 1. & Berat Jenis $\left(\mathrm{gr} / \mathrm{cm}^{3}\right)$ & 2,62 & Min. 2,5 \\
\hline 2. & Penyerapan $(\%)$ & 1,12 & Max. 3 \\
\hline
\end{tabular}

Tabel 2. Hasil Pengujian Aspal Keras Penetrasi 60/70

\begin{tabular}{|c|l|c|c|c|}
\hline \multirow{2}{*}{ No. } & \multicolumn{1}{|c|}{ Pengujian } & \multirow{2}{*}{$\begin{array}{c}\text { Hasil } \\
\text { Pengujian }\end{array}$} & \multicolumn{2}{c|}{ Spesifikasi } \\
\cline { 4 - 5 } & & Min & Maks \\
\hline 1. & Berat Jenis $\left(\mathrm{gr} / \mathrm{cm}^{3}\right)$ & 1,03 & 1 & - \\
\hline 2. & Penetrasi $(\mathrm{mm})$ & 64 & 60 & 79 \\
\hline 3. & $\begin{array}{l}\text { Penetrasi Setelah } \\
\text { Kehilangan Berat } \\
(\mathrm{mm})\end{array}$ & 65,6 & 54 & - \\
\hline 4. & Titik Lembek $\left({ }^{\circ} \mathrm{C}\right)$ & 54,45 & 48 & 58 \\
\hline 5. & $\begin{array}{l}\text { Titik Lembek } \\
\text { Setelah Kehilangan } \\
\text { Berat }\left({ }^{\circ} \mathrm{C}\right)\end{array}$ & 53,6 & 48 & 58 \\
\hline 6. & Titik Nyala $\left({ }^{\circ} \mathrm{C}\right)$ & 326,5 & 200 & - \\
\hline 7. & Daktilitas $(\mathrm{cm})$ & 140 & 100 & - \\
\hline 8. & $\begin{array}{l}\text { Daktilitas Setelah } \\
\text { Kehilangan Berat } \\
(\mathrm{cm})\end{array}$ & 62,86 & 50 & - \\
\hline 9. & $\begin{array}{l}\text { Kehilangan Berat } \\
\text { Aspal }(\%)\end{array}$ & 0,38 & - & 0,8 \\
\hline
\end{tabular}

\section{3) Penentuan Kadar Aspal Optimum}

Kadar aspal optimum diperoleh dengan mengambil beberapa indikator Marshall antara lain Stabilitas, Flow, Marshall Quotient, VIM, dan VMA yang memenuhi syarat dan diambil nilai yang paling ideal. Tabel 3 merupakan hasil pengujian yang telah dilakukan, yang memperoleh nilai kadar aspal optimum sebesar $6,03 \%$.

\section{4) Pengujian Marshall Benda Uji Kontrol}

Hasil pengujian dari parameter Marshall benda uji kontrol dapat dilihat pada Tabel 4 berikut:

Tabel 4. Hasil Pengujian Marshall Benda Uji Kontrol

\begin{tabular}{|l|l|c|c|c|}
\hline \multirow{2}{*}{ No. } & \multicolumn{1}{|c|}{$\begin{array}{c}\text { Data } \\
\text { Marshall }\end{array}$} & $\begin{array}{c}\text { Hasil } \\
\text { Pengujian }\end{array}$ & \multicolumn{2}{|c|}{ Spesifikasi } \\
\cline { 4 - 5 } & Stabilitas (kg) & $2379-2694$ & 800 & Maks. \\
\hline 2. & Flow (mm) & $1,34-3,87$ & 3,0 & - \\
\hline 3. & $\begin{array}{l}\text { Marshall } \\
\text { Quotient } \\
\text { (kg/mm) }\end{array}$ & $1953-687$ & 250 & - \\
\hline 4. & VIM (\%) & $19,68-3,27$ & 3 & 6 \\
\hline 5. & VMA (\%) & $21,97-20,48$ & 18 & - \\
\hline 6. & VFA (\%) & $10,43-84,01$ & 68 & - \\
\hline 7. & $\begin{array}{l}\text { Kadar Aspal } \\
\text { Optimum }(\%)\end{array}$ & 6,03 & \multicolumn{2}{l}{} \\
\hline
\end{tabular}


Tabel 3. Penentuan Kadar Aspal Optimum

\begin{tabular}{|c|c|c|c|c|c|c|c|c|c|}
\hline \multicolumn{10}{|c|}{ Penentuan Kadar Aspal Optimum } \\
\hline \multirow{2}{*}{$\begin{array}{c}\text { Parameter } \\
\text { Marshall }\end{array}$} & \multirow{2}{*}{ Satuan } & \multicolumn{2}{c|}{ \% Kadar Serbuk Ban Terhadap Berat Campuran } & \multicolumn{2}{|c|}{ Spesifikasi } \\
\cline { 2 - 11 } & & $\mathbf{4}$ & $\mathbf{4 , 5}$ & $\mathbf{5}$ & $\mathbf{5 , 5}$ & $\mathbf{6}$ & $\mathbf{6 , 5}$ & Min. & Max. \\
\hline Stabilitas & $\mathrm{kg}$ & 2379 & 2383 & 2425 & 2417 & 2436 & 2694 & 800 & - \\
\hline Flow & $\mathrm{mm}$ & 1,34 & 1,53 & 2,87 & 3,54 & 3,68 & 3,87 & 3 & - \\
\hline $\begin{array}{c}\text { Marshall } \\
\text { Quotient }\end{array}$ & $\mathrm{kg} / \mathrm{mm}$ & 1953 & 1590 & 846 & 680 & 663 & 697 & 250 & - \\
\hline VIM & $\%$ & 19,68 & 15,75 & 10,96 & 6,97 & 3,56 & 3,27 & 3 & 6 \\
\hline VMA & $\%$ & 21,97 & 21,31 & 20,32 & 19,75 & 19,46 & 20,48 & 18 & - \\
\hline VFA & $\%$ & 10,43 & 26,10 & 46,06 & 64,96 & 81,71 & 84,01 & 68 & - \\
\hline
\end{tabular}

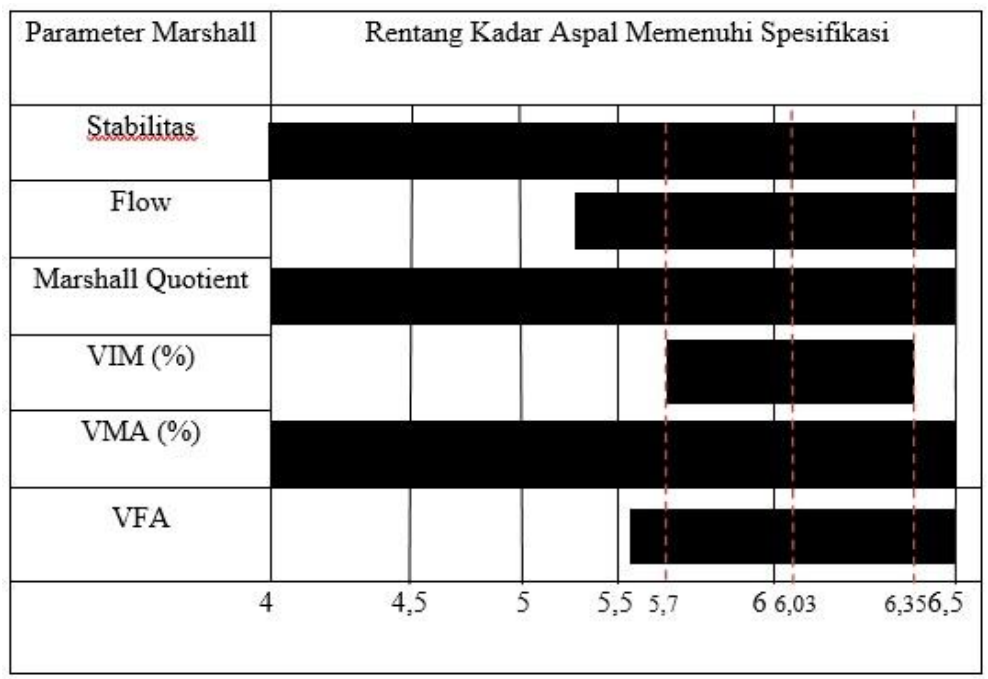

Gambar 1. Kadar Aspal Optimum

5) Hasil Pengujian Marshall Benda Uji Penelitian

Tambahan Serbuk Ban Bekas 0\%, 1,5\%, 3\%, $4,5 \%$, dan $6 \%$

Hasil pengujian dari parameter Marshall benda uji penelitian dengan tambahan serbuk ban bekas $0 \%, 1,5 \%$, $3 \%, 4,5 \%$, dan $6 \%$ diperoleh hasil sesuai pada Tabel 5 di bawah ini:

Tabel 5. Hasil Pengujian Marshall Benda Uji Penelitian

\begin{tabular}{|c|l|c|c|c|}
\hline \multirow{2}{*}{ No. } & \multirow{2}{*}{$\begin{array}{c}\text { Data } \\
\text { Marshall }\end{array}$} & \multirow{2}{*}{$\begin{array}{c}\text { Hasil } \\
\text { Pengujian }\end{array}$} & \multicolumn{2}{c|}{ Spesifikasi } \\
\cline { 4 - 5 } & Min. & Maks. \\
\hline 1. & Stabilitas (kg) & $2224-1075$ & 800 & - \\
\hline 2. & Flow (mm) & $3,98-4,60$ & 3,0 & - \\
\hline 3. & $\begin{array}{l}\text { Marshall } \\
\text { Quotient } \\
\text { (kg/mm) }\end{array}$ & $552-228$ & 250 & - \\
\hline 4. & VIM (\%) & $4,01-1,95$ & 3 & 6 \\
\hline 5. & VMA (\%) & $19,70-18,85$ & 18 & - \\
\hline 6. & VFA (\%) & $79,67-89,63$ & 68 & - \\
\hline
\end{tabular}

\section{PEMBAHASAN}

1) Penambahan Serbuk Ban Bekas Berdasarkan Parameter Marshall Stabilitas

Sukirman (2007) pengujian nilai stabilitas adalah kemampuan maksimum beton aspal padat menerima beban sampai terjadi kelelehan plastis. Berdasarkan Tabel
5 saat campuran $0 \%$ nilai stabilitas $2224 \mathrm{~kg}$, kemudian mengalami kenaikan pada kadar serbuk ban $1,5 \%$ sebesar $2296 \mathrm{~kg}$, selanjutnya pada kadar serbuk ban $3 \%$ mengalami penurunan stabilitas menjadi $1674 \mathrm{~kg}$, kadar serbuk ban 4,5\% nilai stabilitas $1055 \mathrm{~kg}$, dan kadar serbuk ban $6 \%$ nilai stabilitas menjadi $1075 \mathrm{~kg}$. Hal ini disebabkan karena serbuk ban terlalu banyak sehingga menyebabkan film aspal bertambah tipis yang mempengaruhi daya ikat aspal dan penguncian antar agregat semakin berkurang. Kadar penambahan serbuk ban telah memenuhi spesifikasi Pelaksanaan Lapis Campuran Beraspal Panas Revisi SNI 03-1737-1989, stabilitas minimal $800 \mathrm{~kg}$.

Hal ini diperkuat penelitian Faisal, dkk (2014) bahwa penggunaan parutan ban dalam bekas kendaraan roda empat dapat membantu meningkatkan nilai stabilitas.

\section{2) Flow}

Sukirman (2007) flow adalah besarnya perubahan plastis dari beton aspal padat akibat adanya beban sampai batas keruntuhan. Berdasarkan Tabel 5, semakin banyak kadar serbuk ban, nilai flow menunjukkan peningkatan mulai dari $0 \%$ sampai 3\%. Kadar serbuk ban $0 \%$ nilai flow 3,98mm, kadar serbuk ban $1,5 \%$ nilai flow $4,53 \mathrm{~mm}$, kadar serbuk ban $3 \%$ nilai flow $4,57 \mathrm{~mm}$, kemudian pada kadar serbuk ban $4,5 \%$ nilai flow mengalami penurunan yaitu $4,45 \mathrm{~mm}$, selanjutnya kadar serbuk ban $6 \%$ nilai flow 
meningkat kembali menjadi 4,60 mm. Nilai flow tertinggi dengan tambahan serbuk ban bekas adalah 4,60mm, sedangkan nilai flow terrendah tanpa tambahan serbuk ban bekas adalah $3,87 \mathrm{~mm}$. Hasil tersebut menunjukkan bahwa kadar penambahan serbuk ban memenuhi spesifikasi Pelaksanaan Lapis Campuran Beraspal Panas Revisi SNI 03-1737-1989, dengan nilai flow minimal $3 \mathrm{~mm}$.

Faisal, dkk (2014) tambahan parutan ban dalam bekas kendaraan roda empat untuk nilai flow aspal beton AC$\mathrm{BC}$ menunjukkan peningkatan dari penggunaan $0 \%$ sebesar $3,6 \mathrm{~mm}$, parutan ban dalam bekas $1 \%$ naik menjadi 4,3mm, kemudian terus menurun secara signifikan mulai dari $2 \%$ dengan nilai flow 4,1 sampai $5 \%$ dengan nilai flow $3,3 \mathrm{~mm}$.

\section{3) MQ (Marshall Quotient)}

Marshall Quotient adalah perbandingan antara nilai stabilitas dengan nilai flow (Sukirman, 2007). Nilai MQ pada Tabel 5 dapat dilihat bahwa semakin banyak penambahan serbuk ban yang digunakan, maka nilai MQ cenderung semakin menurun dan nilai MQ terendah yaitu pada kadar serbuk ban $6 \%$ sebesar $228 \mathrm{~kg} / \mathrm{mm}$. Kadar serbuk ban $4,5 \%$ dan $6 \%$ tidak memenuhi spesifikasi yang ditentukan Pelaksanaan Lapis Campuran Beraspal Panas Revisi SNI 03-1737-1989, dengan syarat MQ minimal $250 \mathrm{~kg} / \mathrm{mm}$.

Faisal, dkk (2014) nilai MQ campuran aspal beton AC-BC dengan variasi parutan ban dalam bekas kendaraan roda empat turun dari $0 \%$ sampai $1 \%$, kemudian meningkat kembali pada $1 \%$ hingga $5 \%$. Nilai MQ tertinggi diperoleh pada $5 \%$ yaitu $734,96 \mathrm{~kg} / \mathrm{mm}$ dan terendah pada $1 \%$ yaitu $479,77 \mathrm{~kg} / \mathrm{mm}$, kemudian meningkat kembali hingga $5 \%$ parutan ban dalam bekas kenderaan roda 4. Nilai MQ campuran aspal beton AC$\mathrm{BC}$ dari semua variasi parutan ban dalam bekas kendaraan roda 4 masih memenuhi persyaratan untuk nilai MQ yaitu $>250 \mathrm{~kg} / \mathrm{mm}$.

\section{4) VIM (Void In Mix)}

Lengkung VMA yang akan turun sampai mencapai nilai minimum dan kemudian kembali bertambah dengan bertambahnya kadar aspal (Sukirman, 2007). Nilai VIM pada Tabel 5 bahwa semakin banyak penambahan serbuk ban yang digunakan, maka akan berpengaruh terhadap penurunan nilai VIM, dan yang terendah pada kadar serbuk ban $6 \%$ dengan nilai VIM 1,95\%. Dari semua kadar penambahan, kadar serbuk ban 3\%, 4,5\% dan $6 \%$ tidak memenuhi spesifikasi yang ditentukan Pelaksanaan Lapis Campuran Beraspal Panas Revisi SNI 03-17371989, sebab syarat nilai VIM maksimal $6 \%$ dan minimal $3 \%$.

Faisal, dkk (2014) nilai VIM campuran aspal beton AC-BC dengan variasi parutan ban dalam bekas kenderaan roda empat terjadi penurunan nilai VIM pada setiap penambahan kadar serbuk ban.

\section{5) VMA ( Void In Mineral Agregat)}

VMA yaitu volume rongga yang terdapat diantara butir agregat dari suatu campuran aspal yang telah dipadatkan (Sukirman, 2007). Nilai VMA cenderung mengalami penurunan pada setiap penambahan serbuk ban. Hal ini diperkuat dengan rangkuman data pada Tabel 4.5 nilai VMA terendah yaitu kadar serbuk ban $6 \%$ nilai VMA $18,85 \%$. Semakin bertambah kadar serbuk ban, maka jumlah rongga dalam campuran akan berkurang. Semua rentang kadar tambahan serbuk ban bekas telah memenuhi spesifikasi Pelaksanaan Lapis Campuran Beraspal Panas Revisi SNI 03-1737-1989, dengan syarat VMA minimal $18 \%$.

Gosali, G., dkk. (2016) menyimpulkan dalam penelitiannya bahwa terjadi penurunan nilai VMA pada semua campuran serbuk ban bekas yaitu kadar $1 \%, 2 \%$, dan $3 \%$. Hasil penambahan serbuk ban karet yang memiliki nilai lebih rendah (dibandingkan dengan campuran tanpa karet) hasilnya masih diatas batas spesifikasi minimum, sehingga masih dapat digunakan sebagai campuran lapisan perkerasan.

\section{6) VFA (Void Filled with Asphalt) Penambahan Serbuk Ban Bekas}

VFA merupakan banyaknya pori antara butir agregat didalam beton aspal padat yang terisi oleh aspal (Sukirman, 2007). Nilai VFA pada Tabel 5 menunjukkan bahwa semakin banyak tambahan serbuk ban yang digunakan dalam campuran, maka nilai VFA semakin naik dan nilai VFA tertinggi yaitu pada kadar serbuk ban $6 \%$ dengan nilai VFA 89,63\%. Peningkatan nilai VFA disebabkan dengan penambahan kadar serbuk ban yang dapat mengurangi jumlah rongga dalam campuran. Sehingga, mengakibatkan nilai VFA cenderung mengalami suatu peningkatan. Semua rentang kadar penambahan serbuk ban bekas telah memenuhi spesifikasi Pelaksanaan Lapis Campuran Beraspal Panas Revisi SNI 03-1737-1989, dengan syarat VFA minimal 68\%.

Penelitian Faisal, dkk (2014) nilai VFA terjadi peningkatan seiring dengan bertambahnya persentase parutan ban dalam bekas kendaraan roda empat, walaupun peningkatan nilai VFA tidak terlalu besar. Meningkatnya nilai VFA disebabkan bertambahnya persentase parutan ban dalam bekas kendaraan roda empat dalam campuran aspal beton AC-BC. Hal ini mengakibatkan aspal dan parutan ban dalam bekas kendaraan roda empat banyak mengisi pori-pori atau rongga campuran serta semakin tebalnya selimut material. Nilai VFA masih memenuhi persyaratan untuk campuran aspal beton AC-BC yaitu lebih besar dari $63 \%$.

\section{KESIMPULAN}

1) Penentuan nilai KAO pada campuran HRS-WC berdasarkan parameter Marshall

Penentuan nilai Kadar Aspal Optimum (KAO) sebesar $6,03 \%$ berdasarkan semua hasil stabilitas, kelelehan (flow), Marshall Quotient (MQ), rongga terisi aspal (VFA), rongga dalam campuran (VIM), dan rongga dalam agregat (VMA).

2) Penambahan limbah serbuk ban bekas berdasarkan parameter Marshall

1) Penambahanlimbah serbuk ban bekas $0 \%$ Pada kadar penambahan serbuk ban bekas $0 \%$ nilai stabilitas $2224 \mathrm{~kg}$, flow menunjukkan nilai $3,98 \mathrm{~mm}$, nilai MQ (Marshall Quotient) $552 \mathrm{~kg} / \mathrm{mm}$, nilai VIM (Void in Mixture) 4,01\%, VMA (Void in Mineral 
Agregate) 19,70\%, sedangkan VFA (Void Filled with Asphalt) $79,67 \%$.

2) Penambahan limbah serbuk ban bekas $1,5 \%$

Pada kadar penambahan serbuk ban bekas $1,5 \%$ nilai stabilitas $2296 \mathrm{~kg}$, nilai flow 4,53mm, nilai MQ (Marshall Quotient) 509kg/mm, nilai VIM (Void in Mixture) 3,82\%, VMA (Void in Mineral Agregate) 19,63\%, sedangkan VFA (Void Filled with Asphalt) $80,54 \%$.

3) Penambahan limbah serbuk ban bekas $3 \%$

Pada kadar penambahan serbuk ban bekas 3\% nilai stabilitas $1674 \mathrm{~kg}$, nilai flow $4,57 \mathrm{~mm}$, nilai MQ (Marshall Quotient) 367kg/mm, nilai VIM (Void in Mixture) 2,78\%, VMA (Void in Mineral Agregate) 19,20\%, sedangkan VFA (Void Filled with Asphalt) $85,50 \%$.

4) Penambahan limbah serbuk ban bekas $4,5 \%$

Pada kadar penambahan serbuk ban bekas $4,5 \%$ nilai stabilitas $1055 \mathrm{~kg}$, nilai flow $4,45 \mathrm{~mm}$, nilai MQ (Marshall Quotient) 247kg/mm, nilai VIM (Void in Mixture) 2,42\%, VMA (Void in Mineral Agregate) 19,04\%, sedangkan VFA (Void Filled with Asphalt) $87,30 \%$.

5) Penambahan limbah serbuk ban bekas $6 \%$

Pada kadar penambahan serbuk ban bekas $6 \%$ nilai stabilitas $1075 \mathrm{~kg}$, nilai flow 4,60mm, nilai MQ (Marshall Quotient) 228kg/mm, nilai VIM (Void in Mixture) 1,95\%, VMA (Void in Mineral Agregate) 18,85\%, sedangkan VFA (Void Filled with Asphalt) $89,63 \%$.

\section{DAFTAR PUSTAKA}

Departemen Pekerjaan Umum Tahun 1989. Pelaksanaan Lapis Campuran Beraspal Panas Revisi SNI No.03 1737-1989. Jakarta: Yayasan Badan Penerbit Pekerjaan Umum Jakarta. (Online), http://www.pdfoz.net/k-14431257.html, diakses 23 April 2020.

Faisal, Sofyan, M.Shaleh, M. I. (2014). Karakteristik Marshall Campuran Aspal Beton Ac-Bc Menggunakan Material Agregat. Jurnal Teknik Sipil, Pascasarjana Universitas Syiah Kuala, ISSN 23020253, 3(3), 38-48.

Gosali, G., Jaya, H., Wulandari, P. S., \& Patmadjaja, H. (2016). Pengaruh Penambahan Serbuk Ban Karet Mesh \#80 Pada Campuran Laston Untuk Perkerasan Jalan Raya. Jurnal Dimensii Pratama Teknik Sipil, 5(1), 1-8.

Hasib. 2008. Pengaruh Penambahan Ban Karet pada Laston Ditinjau Terhadap Parameter Marshall. Skripsi. Tidak diterbitkan. Malang: Universitas Negeri Malang.

Kencana, Maulandy R.B. 2018. Usul HPJI agar Fasilitas Jalan Tak Cepat Rusak, (Online), https://www.liputan6.com, diakses 23 April 2020.

Leksminingsih. (2001). Pengaruh Penambahan Katalis Bekas (SPENT CATALYST) terhadap Kinerja Beraspal. In Skripsi, (Online), http://www.lontar.ui.ac.id, diakses 23 April 2020.
Mashuri, \& Batti. (2011). Pemanfaatan Material Limbah Pada Campuran Panas. Makalah Ilmiah Teknik Sipil. (3): 204-212.

Nurdin Bukit dan Erna Frida. (2011). Pengolahan ban bekas berwawasan lingkungan menjadi bahan bamper pada outomotif. Jurnal Teknologi Indonesia, 34, 123131.

Sukirman, S. 2007. Beton Aspal Campuran Panas. Jakarta: Yayasan Obor Indonesia.

Suryadharma, H. dan Susanto, B. 1999. Rekayasa Jalan Raya. Yogyakarta: Universitas Atma Jaya. 
Jurnal Rekayasa Tenik Sipil Universitas Madura Vol.5 No.1 Juni 2020 ISSN 2527-5542

Halaman Ini Sengaja Dikosongkan 